$$
\begin{gathered}
\text { "If Funded, } \\
\text { Operations Office } \\
\text { Copyr }
\end{gathered}
$$

DOE/ER/13465-9

\title{
MAGNETIC RESONANCE AND OPTICAL SPECTROSCOPIC STUDIES OF CAROTENOIDS
}

\author{
Progress Report
}

December 1, 1991 - November 30, 1994

Lowell D. Kispert, Principal Investigator

Department of Chemistry

The University of Alabama

Tuscaloosa, Alabama 35487

May 1994

Prepared for the U. S. Department of Energy

Under Grant Number DE-FG05-86ER13465 


\section{INTRODUCTION:}

anowis

It is our goal to study the role of the host lattice in the formation of carotenoid cation radicals, dications, and excited singlet states. Particular emphasis is being placed on determining what is special about carotenoids that natural photosynthetic systems require them for photoprotection and also as components for electron transport processes. We are thus manipulating the host matrix so as to characterize the function and the structure of carotenoids and their cation radicals and dications in different dielectric media. To understand their properties, we have carried out Simultaneous Electrochemistry and Electron Paramagnetic Resonance (SEEPR), Simultaneous Electrochemistry and Optical Spectroscopy; Simultaneous Electrochemistry and Resonance Raman, Electron-Nuclear Double Resonance (ENDOR), Chemically Induced Dynamic Electron Polarization (CIDEP), two dimensional NMR, and optical measurements of carotenoids and carotenoid cation radicals. Carotenoid excited states were formed optically and studied by picosecond spectroscopy in different dielectric media. The carotenoid cation radicals were formed electrochemically, photolytically, catalytically, and radiolytically in different host matrices.

The structures of carotenoids available to us from commercial or philanthropically inclined sources differ so widely that the effects of a particular feature cannot be systematically assessed. In order to reduce the structural variables, several novel carotenoids were synthesized. Most are unsymmetrical 7'-apo-7'phenyl- $\beta$-carotenes in which the phenyl ring is substituted with different electronwithdrawing or electron-donating groups.

\section{SOURCES OF KEY MATERIALS}

The structures of the relevant compounds are shown in Charts I and II. The parent compound, $\beta$-carotene (I), and compounds II-V were purchased from either Sigma or Fluka. 8'-Apo- $\beta$-caroten-8'-al (V) was also obtained by extracting a $20 \%$ oil suspension sold as cheese food coloring by Roche Vitamins and Fine Chemicals, Nutley, NJ. $\beta$-Cryptoxanthin (VI) and zeaxanthin (VII) came from the Argonne National Lab photosynthesis group (Mike Wasielewski). Drs. Holick and Keller (Hoffmann-La Roche, Basel, Switzerland) generously provided samples of crocetindialdehyde (VIII), its 15,15'-didehydro analogue (IX), 15,15'-didehydro- $\beta$ carotene $(X)$, isozeaxanthin (XI), echinenone (XII), rhodoxanthin (XIII), and lycopene (IV). These materials were especially useful in our earlier studies.

The compounds shown in Chart II were synthesized in our laboratory. 7'Apo-7'-7'-dicyano- $\beta$-carotene (XIV) was initially prepared by and obtained from Dr. Wasielewski's group. 


\section{DISCLAIMER}

Portions of this document may be illegible in electronic image products. Images are produced from the best available original document. 
Chart I

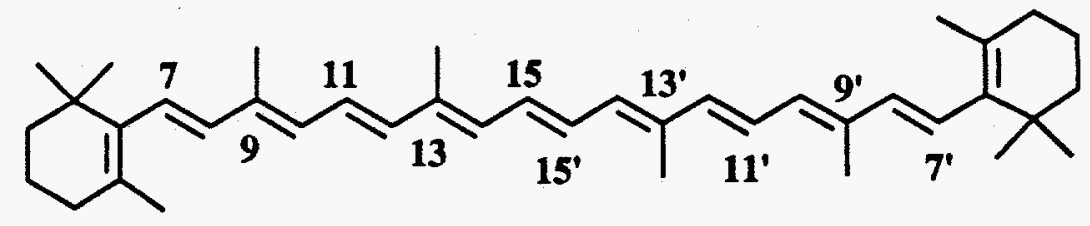

(I)

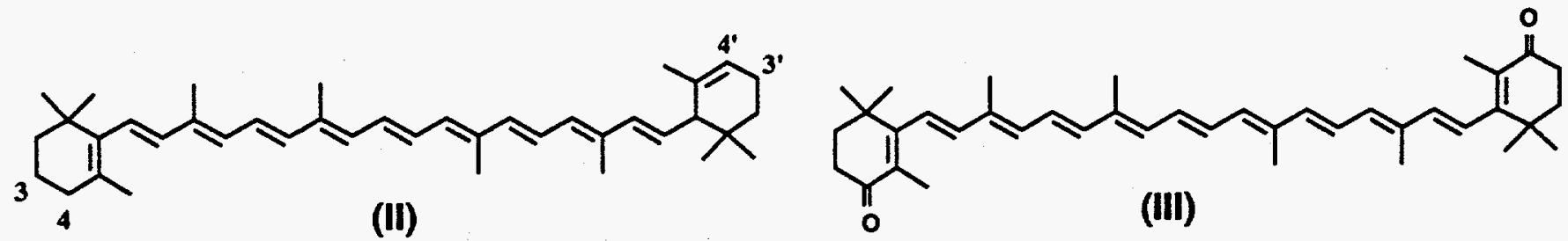

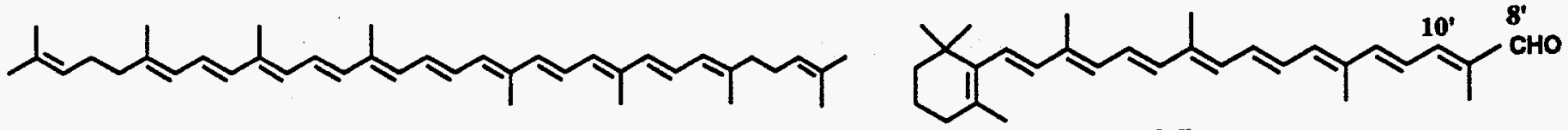

(IV)

(v)

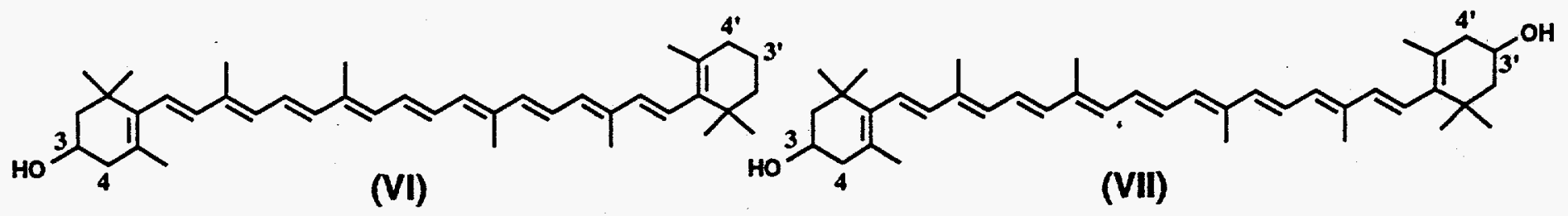

$\underbrace{(N}_{\text {(VIII) }}$

$\mathrm{X}_{(\mathrm{x})}$
$\underbrace{1}_{(\mathrm{IX})}$

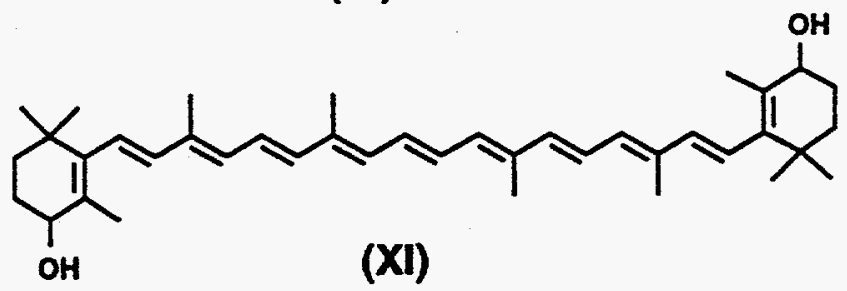

(XI)

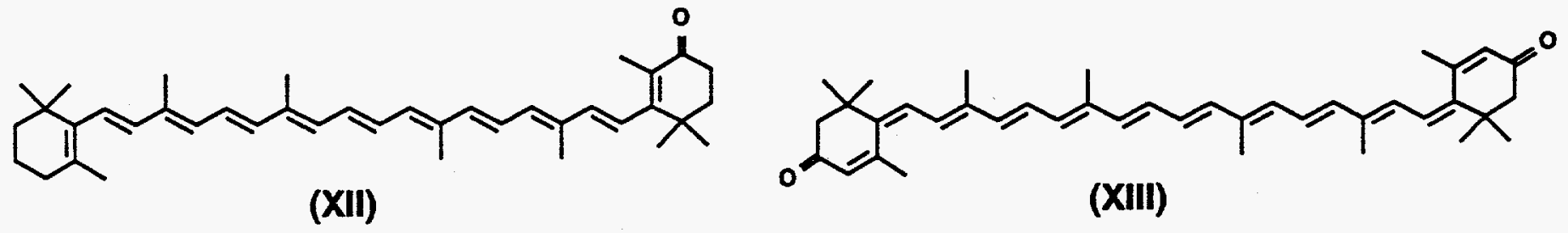


Chart II<smiles>CC1=C(/C=C/C(C)=C/C=C/C(C)=C/C=C/C=C(C)/C=C/C=C(\C)C=C(C#N)C#N)C(C)(C)CCC1</smiles><smiles>CC(/C=C\c1ccccc1)=C\C=C\C(C)=C\C#C/C=C(C)/C=C/C=C(C)/C=C/c1ccccc1</smiles><smiles>[X]c1ccc(/C=C/C(C)=C/C=C/C(C)=C/C=C/C=C(C)/C=C/C=C(C)/C=C\C2=C(C)CCCC2(C)C)cc1</smiles><smiles>CC1=C(/C=C/C(C)=C/C=C/C(C)=C/C=C/C=C(C)/C=C/C=C(C)/C=C/[Bi])C(C)(C)CCC1</smiles>

$$
\begin{aligned}
& A r=C_{6} H_{5} \\
& A r=C_{6} F_{5}
\end{aligned}
$$$$
A r=2,4,6-\left(\mathrm{CH}_{3}\right)_{3} \mathrm{C}_{6} \mathrm{H}_{2}(X X I)
$$<smiles>CC(/C=C\c1ccccc1)=C\C=C\C(C)=C\C=C\C=C(C)\C=C\C=C(C)\C=C\c1ccccc1</smiles> 


\section{SUMMARY OF STUDIES PUBLISHED, ACCEPTED OR SUBMITTED FOR PUBLICATION, AND PAPERS PRESENTED (1991-1994).}

Papers published, accepted or submitted (\#1-19) on the work supported by the grant, abstracts to papers presented at meetings (\#20-35) and manuscripts in preparation (\#36-38) are listed starting on page 10. A brief summary of the new results in each area is given below. The expertise of Dr. A. Jeevarajan in laser spectroscopy, transient radical chemistry, and EPR spectroscopy and the synthetic ability of Dr. Elli Hand (part-time) has increased our productivity this past funding period. Currently all equipment is operational except the ENDOR system and the research effort has run smoothly except from April to June 1993 (explained later).

\section{STRUCTURE DETERMINATIONS}

The structures of the novel (Chart II) carotenoids were established by one- and two-dimensional ${ }^{1} \mathrm{H}$ and ${ }^{13} \mathrm{C}$ NMR studies; details of the syntheses and the measurements and interpretation of the changes in NMR chemical shifts upon donor/acceptor substitution were discussed in four papers $(\# 5,6,8,9)$ and one presentation (\#23). The effect of the terminal strong electron acceptors $[C=O(V)$ and $\left.\mathrm{C}=\mathrm{C}(\mathrm{CN})_{2}(\mathrm{XIV})\right]$ on the structure of carotenoids and the molecular features which control their photochemical properties were presented in \#5, while the chemical shifts of the $7^{\prime}$-substituted aryl carotenoids (XVI - XXII) were given in \#6. The preparation of the 7,7'-diphenyl carotenoids (XV and XXIII) and their structure determination were described in \#8, while the effects of electron-donating and electron-withdrawing groups, attached to one terminal phenyl substituent, on the NMR parameters of carotenoids (XVI - XXII) are given in \#9.

\section{SIMULTANEOUS ELECTROCHEMICAL AND ELECTRON PARAMAGNETIC RESONANCE (SEEPR) STUDIES}

The results of extensive studies of the effect of donor/acceptor groups, acetylenic, keto and hydroxy substitutents on the equilibrium constant $(\mathrm{K})$ for the reaction $\mathrm{CAR}^{++}+\mathrm{CAR}_{-}^{\mathrm{K}^{\prime}} 2 \mathrm{CAR}^{+\cdot}$ are discussed in detail in two chapters of Mazen Khaled's Ph.D. dissertation (\#4), in one chapter of Xinhai Chen's M. S. thesis (\#3), in publications $\# 16,17$, and 18, several conference presentations ( $\# 23,25,27,29,31$, and 35 ) and a paper now in preparation (\#38). According to SEEPR measurements in a dichloromethane solution, $K^{\prime}$ lies far to the left $\left(K^{\prime} \sim 10^{-2}\right.$ to $\left.10^{-5}\right)$ for carotenoids with electron donors but lies to the right $\left(K^{\prime} \sim 2 \times 10^{3}\right)$ for electron-acceptor substituents like in canthaxanthin (III). The electron-donor substituted carotenoids are more easily oxidized than the electron-acceptor substituted carotenoids. The greater the number of keto groups present at the end of the polyene conjugation (III vs. XII), the more stable the cation radicals and the less stable the dications. The same is true when an additional double bond is present in the carotenoid (XIII). The long 
polyene chain accommodates the distribution of two positive charges with little unpaired electron density occurring near the terminal keto groups. On the other hand, the ratio of the concentrations $C A R^{+} \cdot / \mathrm{CAR}^{++}$decreases when hydroxyl groups are present in the terminal cyclohexene rings (VI, VII, and XI). The substitution of a triple bond $(X)$ for a double bond (I) in the center of the polyene chain decreases $K^{\prime}$ by 2 orders of magnitude.

During the time required for SEEPR studies, (5-10 min.) processes other than the above single equilibrium can occur. The measured oxidation potentials and cation radical concentrations reflect the results of all reactions, those occurring independently of one another, those coupled to others, at the electrodes as well as in the bulk of the solution.

\section{SIMULATION}

Considerable insight was gained into the interpretation of the magnitude of $K^{\prime}$ deduced by SEEPR measurements after Steve Feldberg's (Brookhaven National Laboratory) CV "DigiSim" program became available for our use through Bioanalytical Systems. This simulation program permits description of the overall system in terms of individual processes. It was found that more accurate first and second oxidation potentials and more consistent $\mathrm{K}_{\mathrm{com}}$ (comproportionation) and $\mathrm{K}_{\mathrm{dp}}$ (deprotonation) equilibrium constants could be deduced if the system is comprised of three electrode reactions and two or, in the case of the acetylenic compounds, three homogeneous equilibria (\#38). Although the general trend in the values of $K_{\text {com }}$ as a function of substituent was retained, the magnitude was substantially different. $K_{\text {com }}^{\prime}$ values deduced from SEEPR data reflect the stability of carotenoid cation radicals in the bulk solution, while $K_{\text {com }}$ values from $C V$ simulation reflect the cation radical concentration measured at the electrode.

\section{ENDOR AND EPR STUDY OF CAROTENOID CATION RADICALS}

We have reported the first observation of a solution ENDOR spectrum of an electrochemically prepared cation radical $(\# 10,26,34)$. The ENDOR spectrum was made possible by prolonged electrolysis of a concentrated solution of canthaxanthin (III) in dichloromethane, taking advantage of the favorable equilibrium constant ( $\mathrm{K}$ $\sim 2 \times 10^{3}$ ) for the formation of cation radicals. The high concentration of carotenoid in solution required to obtain ENDOR (or EPR) spectra, causes spin exchange effects which made it impossible to observe coupling constants smaller than $1 \mathrm{MHz}$. The isotropic hyperfine coupling constants of the methyl protons are in reasonable agreement with those calculated by RHF-INDO/SP molecular orbital methods for a planar all-trans polyene $\pi$-cation radical structure.

EPR and ENDOR spectra, were obtained by photochemically generating radicals from carotenoids (deposited on) Nafion film and silica gel $(\# 2,20,21)$. The 
ENDOR spectra were analyzed by comparison to the calculated powder ENDOR spectrum using the computer simulation program from the Illinois EPR Research Center $(\# 2,20,21)$. Coupling assignments were made by reference to the RHFINDO/SP calculations carried out in Berlin. These are superior to the INDO calculations for estimating ENDOR coupling constants.

The radical cations of canthaxanthin (III), $\beta$-carotene (I), and 8'-apo- $\beta$-caroten$8^{\prime}$-al (V) were also spontaneously generated when the neutral compounds were deposited on an activated silica-alumina solid support matrix. Formation of radical cations is attributed to the higher concentration of Lewis acidic sites in this matrix, while the relatively large concentration of the radical cations is due to Brönsted acids which destabilized the dications and thus shift the comproportionation equilibrium to the right $(\# 11,19,26,29,32,33)$. It was determined by computer simulation of the ENDOR spectra that the orientation of the carotenoid radical cation on the surface of the matrix depends on the substituent.

The two large ENDOR book chapters (\#12,13) completed some time ago for the Handbook of Electron Spin Resonance were published in May, 1994 by the American Institute of Physics.

\section{CIDEP STUDIES}

The results of time-resolved electron paramagnetic resonance (TREPR) measurements of radical cations with lifetimes of $2 \mu \mathrm{s}$ formed by the $308 \mathrm{~nm}$ photoexcitation of several donor/acceptor substituted carotenoids in $\mathrm{CCl}_{4}$ solution have been reported $(\# 7,24)$. Further details are given in the Ph.D. dissertation (\#4). The polarized CIDEP spectra were interpreted in terms of radical pair formation between a radical anion of the solvent $\left(\mathrm{CCl}_{4}\right)$ and the carotenoid cation radical. The $\mathrm{g}$ factors and the line widths are consistent with the EPR data of the electrochemically generated radical cations with lifetimes of minutes in a $\mathrm{CH}_{2} \mathrm{Cl}_{2}$ solvent if the spectrum of the radical anion of the solvent $\mathrm{CCl}_{4}$ is considered as part of the polarized spectrum (\#7). The reason for the large variation in lifetime of the carotenoid radical cations is not understood, but a large dependence on the nature of the host matrix is implied. A large number of the spectra was determined with $M$. Forbes' spectrometer at The University of North Carolina before the rf noise problem in our own spectrometer was solved.

\section{PICOSECOND OPTICAL ABSORPTION MEASUREMENTS}

Optical measurements of the lifetime of the lowest excited singlet state of the highly polarizable polyene $7^{\prime}, 7^{\prime}$-dicyano-7'-apo- $\beta$-carotene (XIV) as a function of solvent dielectric constant at $295 \mathrm{~K}$ and as a function of increasing temperature showed a significant decrease in lifetime as the solvent dielectric constant was increased (\#1). These results prompted us to carry out AM1 calculations on the 
geometry optimized ground state, and the first and second excited states of $\mathrm{V}$ and XIV. The calculations showed a large increase in dipole moment between the ground and the lowest excited singlet states. This provides a reason for the strong dependence of the $S_{1}$ lifetime on the solvent dielectric: greater stabilization of the polar excited state $S_{1}$ occurs and results in enhanced charge transfer character within the excited state, which in turn enhances non-radiative decay of the excited state (\#1). This recent observation may provide a reason for the ubiquitous presence of cisoid carotenoids in plants: energy transfer is enhanced because generally cis forms have larger dipole moments than the all trans forms.

\section{AM1, INDO AND RHF-INDO/SP MOLECULAR ORBITAL CALCULATIONS}

The availability of very generous amounts of computer time on the Alabama Supercomputer Network permitted extensive AM1 and INDO MO calculations to be carried out.

It has been found by AM1 calculations ( $\# 4,22,28,37)$ that the carotenoids with small dipole moment in the ground state possess the largest dipole moment in a $90^{\circ}$ out of plane twisted structure. This was especially true for non-symmetric carotenoids. It should be noted that Deisenhofer found that the structure of the carotenoid imbedded in the reaction center from Rhodopseudomonas viridis is in such a gas phase energetically unfavorable configuration. This suggests that the carotenes will be found in a configuration that generates the largest dipole to ensure compatibility with the polar protein matrix.

Radical cation hyperfine coupling constants were calculated by INDO and RHF-INDO/SP methods using the minimum energy geometry deduced by an AM1 calculation of the cation radical. The results were used to interpret the ENDOR spectra $(\# 2,4,10,11,19,20,28,29)$.

High quality RHF-INDO/SP molecular orbital calculations needed to determine accurate unpaired spin densities for the radical cations are possible by a collaborative arrangement with Dr. Martin Plato, research scientist at the Universität, Berlin, Germany. AM1 geometry optimized carotenoid radical structures are sent by electronic mail to Berlin, where a single point RHF-INDO/SP calculation is carried out. Although only a limited number of calculations can be performed in Berlin, the ones done have been invaluable to our understanding of the carotenoid radical cation structure.

A collaborative project with Dr. Eric Bradford, a staff scientist with the State of Alabama Super Computer Center, has been extremely valuable in assisting us in the various AM1 and INDO calculations. 


\section{PRODUCT ANALYSIS OF ELECTROCHEMICAL OXIDATION AND LASER IRRADIATION EXPERIMENTS}

Of the numerous products formed during the electrochemical oxidation of canthaxanthin, the 9-cis and 13-cis isomers, and toluene were identified. It may be noted that toluene, as well as xylenes formed by excision from the polyene chain, are observed in the mass spectra of many carotenoids. The source of the electrochemically generated toluene can be attributed to the same process. Xylenes could not be detected. $\mathrm{HCl}$ was produced from the solvent, $\mathrm{CH}_{2} \mathrm{Cl}_{2}$. The cis isomers of the carotenoids can also be formed without applying an electrical potential, provided $\mathrm{mM}$ concentrations of $\mathrm{HCl}$ are present in $\mathrm{CH}_{2} \mathrm{Cl}_{2}(\# 14,17,28,30)$. Recent attempts have been made to separate and identify the products formed in the excimer laser irradiated carotenoid solutions. While cis isomers have been isolated $(\# 3,30,14)$, their instability continues to be troublesome.

\section{SPECTROELECTROCHEMISTRY OF CAROTENOIDS IN SOLUTION}

Simultaneous electrochemical-optical spectra have been obtained for 5 different carotenoids, three natural ( $\beta$-carotene, canthaxanthin and $8^{\prime}$-apo-caroten- $8^{\prime}$ al) and two synthetic carotenoids in solution at $300{ }^{\circ} \mathrm{K}$. Our aim was to simultaneously observe the optical spectra of the mixture of the carotenoid radical cation and the dication and the relative concentrations of these species, since a controversy has arisen over the assignment of the carotenoid dication optical spectrum. The $D_{0} \rightarrow D_{2}$ and the weak $D_{0} \rightarrow D_{1}$ transitions of the cation radicals have been detected. In addition an upper limit of the molar extinction coefficient of carotenoid dications in solution is estimated to be on the order of $10^{3}$ to $10^{4}$. Further work is needed to establish the value of the extinction coefficient of the dication (\#15, 28, 29, 35).

\section{SIMULTANEOUS ELECTROCHEMISTRY AND RESONANCE RAMAN OF CAROTENOID CATIONS}

Raman measurements of carotenoid cation radicals on electrodes were carried out at the Ames Laboratory of Professor Therese Cotton at Iowa State University. The cation radicals of the carotenoids were electrochemically prepared and the optical absorption spectra were measured in situ at different time intervals. A strong Resonance Raman absorption at $1545 \mathrm{~cm}^{-1}$ suggests delocalization of the unpaired electron throughout the entire carbon backbone, which is consistent with our previous EPR and ENDOR description of the polyene- $\pi$-carotenoid cation radical (\#36). 


\section{DIFFICULTIES THIS PAST YEAR}

The SEEPR, the simultaneous electrochemistry and optical, and the simultaneous electrochemistry and resonance Raman measurements have proven so fruitful that we have delayed carrying out the planned CIDEP studies as a function of exciting laser wavelength and magnetic field. Sufficient amounts of 9 and $13-c i s-8{ }^{\prime}-\beta$-caroten -8 -al were isolated this past summer that picosecond studies at Argonne National Lab would have been possible. Unfortunately the samples were allowed to warm to room temperature for a few days by an inexperienced student and cis isomers were lost. Additional cis isomers are now being isolated. We have also had some difficulty in obtaining samples of carotenoid cation radicals on solid silica-alumina catalyst with sufficient EPR intensity that pulsed ENDOR measurements could be carried out at Bruker in Karlsrühe, Germany. The orientational dependence as a function of carotenoid on the catalyst surface is needed to further interpret some new ENDOR data. More attempts are being made.

A disaster occurred April 2, 1993 when a newly installed safety shower on the third floor of the chemistry building broke a retaining nut and for $45 \mathrm{~min}$ more than 50 gals per minute of water poured into the building with a majority of the water flowing into our ENDOR/molecular modeling laboratory an the first floor. The water flowed into the new laser printer, the MacIntosh Quadra-700 Computer, the ENDOR/ TRIPLE Spectrometer and the new 486-Gateway 2000 which contains all our molecular modeling software.

The months of April and May 1993 were spent drying out the equipment. This required the complete dissemble of the computers and control devices down to individual components. "Luckily" the flood occurred before 8 am when the equipment was turned off (otherwise many components would have shorted out) so recovery was possible without purchase of new equipment. All manuals, books, and stored data on 250 disks were destroyed in the laboratory. The insurance company has promised expertise to recover the data from the disks - now glued to the holders in which they reside. Most manuals and books can be replaced. Some hard-drives, keyboards and print rollers had to be replaced. The Bruker ENDOR works but no longer meets signal/noise specifications and Bruker has provided the insurance company with quotes for replacement of significant portions of the ENDOR spectrometer components.

\section{DISCLAIMER}

This report was prepared as an account of work sponsored by an agency of the United States Government. Neither the United States Government nor any agency thereof, nor any of their employees, makes any warranty, express or implied, or assumes any legal liability or responsibility for the accuracy, completeness, or usefulness of any information, apparatus, product, or process disclosed, or represents that its use would not infringe privately owned rights. Reference herein to any specific commercial product, process, or service by trade name, trademark, manufacturer, or otherwise does not necessarily constitute or imply its endorsement, recommendation, or favoring by the United States Government or any agency thereof. The views and opinions of authors expressed herein do not necessarily state or reflect those of the United States Government or any agency thereof. 


\section{PAPERS PUBLISHED, ACCEPTED OR SUBMITTED FOR PUBLICATION THIS} PAST YEAR (1991 - 1994)

1. M. P. O'Neil, M. R. Wasielewski, M. M. Khaled and L. D. Kispert, "Solvent and Temperature Dependence of the Lowest Singlet State Lifetimes of $7^{\prime}, 7^{\prime}$-Dicyano7'-Apo- $\beta$-carotene," J. Chem. Phys. , 95, 7212 (1991).

2. L. Piekara-Sady, M. M. Khaled, E. G. Bradford, L. D. Kispert and M. Plato, "Comparison of the INDO to the RHF-INDO/SP Derived Proton Hyperfine Couplings for the Carotenoid Cation Radical: Experimental Evidence from ENDOR," Chem. Phys. Letters, 186, 143 (1991).

3. M. S. Thesis, Xinhai Chen, "An Electrochemical, EPR Study of Carotenoids and High Performance Liquid Chromatography Separation of Cis-Trans Isomers of Canthaxanthin," University of Alabama, Dec. 1991.

4. Ph.D. Dissertation Mazen Khaled, "Electrochemical, Transient EPR and AM1 Excited State Studies of Carotenoids," University of Alabama, Dec. 1992.

5. E. S. Hand, K. A. Belmore and L. D. Kispert, "AM1 Electron Density and NMR Spectral Studies of Carotenoids with a Strong Terminal Electron Acceptor," J. Chem. Soc. Perkin Trans. 2, 659 (1993).

6. E. S. Hand, K. A. Belmore and L. D. Kispert, "NMR Chemical Shift Assignments for 7'-substituted Aromatic-7'-apo- $\beta$-carotenes," Magn. Reson. Chem., 31, 516 (1993).

7. A. S. Jeevarajan, M. Khaled, M. D. E. Forbes, and L. D. Kispert, "CIDEP Studies of Carotenoid Radical Cations," Z. Phys. Chemie, 182, 51 (1993). Reprinted in Magnetic Field and Spin Effects in Chemistry R. Oldenbourg Verlag, München, 1993. Part II, p. 51-62.

8. E. S. Hand, K. A. Belmore and L. D. Kispert, "Synthesis and NMR-Spectroscopic Structure Determination of Novel 7,7'-Diphenyl-7,7'-diapo-carotenoids," Helvetica Chimica Acta, 76, 1939 (1993).

9. E. S. Hand, K. A. Belmore, L. D. Kispert, "The Effect of Electron-donating and Electron-withdrawing Substituents on ${ }^{1} \mathrm{H}$ and ${ }^{13} \mathrm{C}$-NMR Chemical Shifts of Novel 7'-Substituted Aromatic-7'-apo- $\beta$-carotenes," Helvetica Chimica Acta, 76, 1928 (1993).

10. L. Piekara-Sady, A. S. Jeevarajan and L. D. Kispert, "An ENDOR Study of the Canthaxanthin Cation Radical in Solution," Chem. Phys. Letters, 207, 173 (1993). 
11. A. S. Jeevarajan, L. D. Kispert and L. Piekara-Sady, "An ENDOR Study of Carotenoid Cation Radicals on Silica-Alumina Solid Supports," Chem. Phys. Letters, 209, 269 (1993).

12. J. Goslar, L. Piekara-Sady and L. Kispert, "ENDOR Data Tables" in Electron Spin Resonance Handbook, Chapter VI, C. P. Poole, Jr. and H. A. Farach, Editors, Am. Inst. Phys., 1994 - May.

13. L. Piekara-Sady and L. D. Kispert, "ENDOR Spectroscopy," in Electron Spin Resonance Handbook, Chapter V, C. P. Poole, Jr. and H. A. Farach, Editors, Am. Inst. Phys., 1994 - May.

14. A. S. Jeevarajan, C. C. Wei and L. D. Kispert, "Geometrical Isomerization of Carotenoids in Dichloromethane," J. Chem. Soc. Perkin Trans. 2 , 861 (1994).

15. A. S. Jeevarajan, L. D. Kispert and Xiangli Wu, "Spectroelectrochemistry of Carotenoids in Solution," Chem. Phys. Letters, 219, 427 (1994).

16. A. S. Jeevarajan, M. Khaled and L. D. Kispert, "Simultaneous Electrochemical and Electron Paramagnetic Resonance Studies of Keto and Hydroxy Carotenoids,"Chem. Phys. Letters, 1994, in press.

17. A. S. Jeevarajan, M. Khaled and L. D. Kispert, "Simultaneous Electrochemical and Electron Paramagnetic Resonance Studies of Carotenoids: Effect of Electron Donating and Accepting Substituents," J. Phys. Chem., 1994, in press.

18. A. S. Jeevarajan, M. Khaled and L. D. Kispert, "Simultaneous Electrochemical and Electron Paramagnetic Resonance Studies of Acetylenic Carotenoids," J. Chem. Soc. Perkin Trans 2, 1994, submitted.

19. L. Piekara-Sady, A. S. Jeevarajan and L. D. Kispert, An ENDOR Study of Cation Radicals of 7',7'-Dicyano and 7'-Phenyl-7'-Apo- $\beta$-Carotene," Chem. Phys. Letters, 1994, submitted.

\section{PAPERS PRESENTED AT CONFERENCES (1991 - 1994)}

33rd Rocky Mountain Conference, EPR Symposium Denver, CO, July 28 - Aug. 2, 1991.

20. "The Structure of Carotenoid Cation Radicals: An ENDOR and Molecular Orbital Study," L. Piekara-Sady, M. Khaled, E. Bradford, L. Kispert and M. Plato. 
23rd Southeastern Magnetic Resonance Conference Georgia State University, Oct. 3$5,1991$.

21. "An ENDOR Study of Acceptor Substitution in the Carotenoid Cation Radical System," L. Piekara-Sady, L. Kispert and M. Plato.

22. "AM1 Molecular Orbital Prediction of the Excited State Dipoles of the Cis Isomers of Carotenoids: Influence on Excited State Lifetimes," M. M. Khaled and L. D. Kispert.

16th DOE Solar Photochemistry Research Conference, Devan, WS, May 31 - June 4, 1992.

23. "Carotenoid and Carotenoid Cation Radicals: Substituent Effects," E. Hand, M. Khaled, A. S. Jeevarajan, K. Ouderkirk, C. Wei, and L. D. Kispert.

International Symposium on Magnetic Field and Spin Effects in Chemistry, University of Konstanz, Konstanz, Germany, July 26-31, 1992.

24. "CIDEP Studies of Carotenoid Radical Cations," A. S. Jeevarajan, M. Khaled, M. D. E. Forbes and L. D. Kispert, talk and poster presentation. Same talk given at the Laboratory of Physical Chemistry, University of Paris (VI) and at Ciba-Geigy Basel, Switzerland, July 1992.

34th Rocky Mountain Conference, EPR Symposium, Denver, CO, Aug. 2-6, 1992.

25. "SEEPR and ENDOR Study of Carotenoid Radical Cations: Substituent Effects," M. Khaled, A. S. Jeevarajan, E. S. Hand, L. Piekara-Sady, and L. D. Kispert.

24th Southeastern Magnetic Resonance Conference Raleigh, NC, October 8-10, 1992.

26. "An ENDOR Study of Carotenoid Radical Cations" A. S. Jeevarajan, L. PiekaraSady and L. D. Kispert.

27. "Simultaneous Electrochemistry and Electron Paramagnetic Resonance Study of Carotenoids as a Function of Substituent," M. Khaled, A. S. Jeevarajan, E. Hand, E. Bradford and L. D. Kispert.

U. S. DOE Review of Solar Photochemistry Research Program, Bethesda, MD, Feb. 23, 1993.

28. "Magnetic Resonance and Optical Spectroscopic Studies of Carotenoids," L. Kispert. 
17th DOE Solar Photochemistry Research Conference, Brainerd, MN, June 6-10, 1993.

29. "Magnetic Resonance Study of Carotenoids and Carotenoid Cation Radicals," L. D. Kispert, A. S. Jeevarajan, E. S. Hand and C. C. Wei.

45th ACS Southeast Regional Meeting: Johnson City, TN, October 17-20, 1993.

30. "Separation and Identification of Solvent Induced Carotenoid Isomers Using Reverse Phase High Performance Liquid Chromatography," C. C. Wei, A. S. Jeevarajan and L. D. Kispert.

31. "Simulation of Cyclic Voltammograms for Carotenoid Cation Radicals and Dications," J. Jeevarajan and L. D. Kispert.

32. "Carotenoid Cation Radical Generated in Solution and on an Activated SilicaAlumina Solid Support," A. S. Jeevarajan, L. Piekara-Sady and L. D. Kispert.

25th SE-Regional Magnetic Resonance Conference, University of Florida, Gainesville, FL, October 29-30, 1993.

33. "An ENDOR Study of Synthetic Carotenoid Cation Radicals," A. S. Jeevarajan, L. Piekara-Sady and L. D. Kispert.

34. "Difficulties of Carrying Out Magnetic Resonance Studies of Carotenoid Cation Radicals," L. D. Kispert, A. S. Jeevarajan, E. Hand and L. Piekara-Sady.

18th DOE Solar Photochemistry Research Conference, Granlibakken Conference Center, Tahoe City, CA, June 5-9, 1994.

35. "Carotenoids: Optical, Electrochemical and Magnetic Resonance Studies," A. S. Jeevarajan, C. C. Wei, J. A. Jeevarajan, G. Gao and L. D. Kispert.

\section{MANUSCRIPTS IN PREPAR.ATION}

36. "Resonance Raman Study of 8'-Apo- $\beta$-Caroten-8'-al Cation Radical," A. S. Jeevarajan, L. D. Kispert, G. Chumanov, C. Zhou and T. M. Cotton.

37. AM1 Calculated Ground State and Excited State Dipole Moments of Carotenoid Isomers: Role of Host Matrix," M. Khaled, A. S. Jeevarajan, L. D. Kispert.

38. Simulation of Cyclic Voltammograms for Carotenoid Cation Radicals and Dications," J. Jeevarajan and L. D. Kispert. 
STUDENTS AND POSTDOCS WHO HAVE WORKED ON THIS PROJECT

(1991 - 1994)

\begin{tabular}{|c|c|c|}
\hline Name & Title & Period of Study \\
\hline Mazen Khaled & Graduate Student & $\begin{array}{l}\text { August } 1988 \text { - December } 1992 \\
\text { Ph.D. - } 1992\end{array}$ \\
\hline C. C. Wei & $\begin{array}{l}\text { Graduate Student } \\
\text { Ph.D. candidate }\end{array}$ & August 1991 - present \\
\hline G. Gao & $\begin{array}{l}\text { Graduate Student } \\
\text { Ph.D. candidate }\end{array}$ & August 1993 - present \\
\hline J. Jeevarajan & $\begin{array}{l}\text { Graduate Student } \\
\text { Ph. D. candidate }\end{array}$ & August 1992 - present \\
\hline Lidia Piekara-Sady & $\begin{array}{l}\text { Postdoctoral Research } \\
\text { Associate from the } \\
\text { Institute of Molecular } \\
\text { Physics, Poznan, Poland }\end{array}$ & $\begin{array}{l}\text { March, } 1990 \text { - July, } 1992 \\
\text { (returned to Poland } \\
\text { end of June) }\end{array}$ \\
\hline A. Jeevarajan & $\begin{array}{l}\text { Postdoctoral - Ph.D. } \\
\text { Notre Dame, May } 1992 \\
\text { Advisor: Richard Fessender } \\
\text { Expertise in EPR Spectroscop }\end{array}$ & November, 1991 - present \\
\hline Elli Hand & $\begin{array}{l}\text { Research Scientist } \\
\text { Ph.D. - Organic chemist } \\
\text { Harvard/Radcliffe, } 1962\end{array}$ & $\begin{array}{l}\text { March, } 1991 \text { - present } \\
\text { Part-time }\end{array}$ \\
\hline Wai-Kam Hung & Visiting Scientist & April 1993 - November 1994 \\
\hline Ruisong Ding & $\begin{array}{l}\text { Visiting Scientist } \\
\text { Polymer Institute, Beijing }\end{array}$ & April 1994 - present \\
\hline Kim Ouderkirk & $\begin{array}{l}\text { Part-time - summer } \\
\text { High school teacher from } \\
\text { Tuscaloosa } \\
\text { HPLC - Separations }\end{array}$ & Summer 1991, 1992 \\
\hline Marjorie Padgett & $\begin{array}{l}\text { Part-time Undergraduate } \\
\text { Assistant }\end{array}$ & $\begin{array}{l}\text { May, } 1988 \text { - May, } 1992 \\
\text { BS - } 1992\end{array}$ \\
\hline Douglas Reigert & Undergraduate & BS 1994 \\
\hline
\end{tabular}

